\title{
MJMR DECODING PARKINSON'S ASSOCIATED HEALTH MESSAGES IN SOCIAL MEDIA PAGES BY MALAYSIAN SERVICE ADMINISTRATORS
}

\author{
M. S. Bexci ${ }^{1 *}$, R. Subramani ${ }^{2}$ \\ Associate Professor, Department of Communication, Lincoln University College, Malaysia ${ }^{l}$ \\ Assistant Professor, Department of Journalism and Mass Communication, Periyar University, India ${ }^{2}$ \\ "Corresponding author's email: bexci@lincoln.edu.my
}

\begin{abstract}
Social media pages serve as a valuable tool for promoting positive behavioural changes among patients. With a splurge of modern communication tools used today, health promoters use social media pages to get more people take preventive healthcare measures or effectively manage illness on its onset. Most of the health messages are twinned between Observed Information (factual details for health education) and Applied Information (prompting health messages directly used by patients) both resulting in improved health outcomes. Further by applying Positive Deviance, an alternative approach to elevate behavioural changes by sharing successful health best practices to patients and care givers are easily achieved. One such disease which needs more communication attention to promote behavioural change is Parkinson's due to its complex and debilitated condition. This research focuses how health messages are used in social media page like Facebook by Parkinson's disease Associations functioning in Malaysia to impart Parkinson's related information through different communication approaches and also examine social media consumption by Parkinson's patients/followers for behavioural changes through a quantitative content analysis. The findings indicate that evidence of behavioural change may not be proved with just Social Media pages, it is found to be more essential for Parkinson's communication discerning rehabilitation therapies. Further, Social Media pages have all vicissitudes to become obsolete if not effectively used and may not be a sufficient communication tool to achieve positive health outcomes in Parkinson's affected patients.
\end{abstract}

Keywords: Social Media Pages, Parkinson's disease, Objective and Applied Information, Positive Deviance Approach, Behavioural Changes

\section{INTRODUCTION}

Parkinson's disease is a progressive nervous system disorder and a non-fatal illness predominately affecting the elderly population. Although the condition is treatable, Parkinson's patients go through a lot of increasing hardship throughout their entire lives having no escape from trembling, stiffness and slowing of movement. In Malaysia, there are about 15,000 to 20,000 Parkinson's patients and expected to increase by $9.5 \%$ by 2020 , as more than $7 \%$ of the population comprises the elderly people. In view of this impending boom, Parkinson's poses a significant health burden for Malaysian government, patient organisations, researchers, and doctors (Kong, 2009).

Over the past decade, Malaysia has seen major advances in the management of Parkinson's disease as treatment modalities have evolved rapidly. However, there is a widespread ignorance among the Malaysian society about the disease (Azmin et al., 2014) that one may simply understand the slowness of movement and trembling of hands as a natural ageing process or as an onset of stroke. Only a two-third of those patients in Malaysia have been rightly diagnosed and treated by doctors. In order to improve the quality of Parkinson's care in Malaysia, it is important to carry reliable information which being the first vital step in managing any illness and to bring positive behavioural change by patient.

Communication Approaches using Objective, Applied Information and Positive Deviance

To meet communication objectives, messages should be targeted towards raising awareness, promoting acceptance and bringing about behavioural change.In other words, health communication outcomes may be 
strategized towards imparting objective and applied information and knowledge. Objective information is to diffuse factual information to promote awareness about a disease (Nkanunye \& Obiechina, 2017). For example, Parkinson's disease predominately affects old people, but the truth is it may also affect the young. Applied information aims to bring positive behavioral change in the patients (Tull, 2017) who become concerned and are motivated to evaluate their own behaviour by using the information on themselves. For instance, a decade back, Parkinson's patients were administered Levodopa right after diagnosis which led to developing an irreversible side effect called Dyskinesia, an involuntary body movement. Today, after the American Academy of Neurology in its treatment guideline for Parkinson's recommends physicians to prescribe Dopamine Agonist for newlydiagnosed patients and postpones the use of Levodopa at the later stage of illness. Today this fear and misconceptions persist among patients that they too might end up developing Dyskinesia as witnessed in the past. When addressing such concerns over the fear of developing complications due to medications, information regarding the use of outdated treatment approach may mitigate living in prolonged fear and motivates patients to communicate freely with their physicians.

Another important communication strategy in dealing Parkinson's disease is adopting Positive Deviance Approach (PDA) to focus on behavioural change among patients and care givers. PDA is based on the observation that there are positive deviants (individuals and group of patients) within the Parkinson's community who's uncommon but successful behaviors or strategies enable them to find better solutions to manage the disease. These patients may be exposed to exactly the same resources and face the same challenges and obstacles (Skrischer, 2016) yet manage their illness better than others. Submitting such information through testimonies to other patients will improve behavioral changes. Such approaches have been widely used to address a large number of health problems like reducing endemic malnutrition, decreasing maternal mortality, cancer screenings, improving mental well-being and controlling communicable diseases (Singhal and Dura, 2017).

\section{Parkinson's Disease Communication in Malaysian Social Media Communities}

Irrespective of factual or applied information, one can see an overload of information dissemination about Parkinson's in the World Wide Web as in case of every other diseases. For the first time in Malaysia, the Lyold Tan Trust fund launched its website www.lloydtantrust.com named after Late Mr. Llyod Tan Pao Chan, a Malaysian Parkinson'spatient who fought for the rights of the Malaysian Parkinson's community. Apart from this website, a blog www.heroteo.com by Mr. Teo Kim Hoe, a Malaysian Parkinson's patient shared his knowledge and experience and a lot of related medical information of the disease. The websites which are a 'read-only web' making content available online for viewing and there is no direct link or communication between the author and the reader. Apart from these websites, Facebook is widely used in health communication. There are Facebook pages owned by Malaysian non-profit communities bringing people with Parkinson's, their caregivers and family members together to share and exchange information on how to cope better with Parkinson's. Facebook remains the most widely used, as of the second quarter of 2018, it has 2.23 billion monthly active users with almost 2 billion active users in Malaysia according to a data from Statista (2018). Typically, Facebook pages are created to promote the interests of an organisation and post information that allows interaction with the shared content with having complete control on what is being discussed by the creators. Furthermore, Facebook administrators can track engagement measures, reach of the content, visibility and impressions of the posts, page like, and video retentions (Facebook.com). Information posted motivates and remind patients to give emphasis on a particular health behavior. The post of patients too will inform as to what sort of information the patient usually asks and if there is any positive change in the health outcomes. For health enthusiasts, Facebook can be an effective reference for obtaining tips and information to keep their health in order (Woolley \& Peterson, 2012; Shute, 2011).

In this context, this research focuses how health messages are used in social media page like Facebook to impart Parkinson's related information through different communication approaches and examine 
social media consumption by Parkinson's patients/followers for behavioural changes.

\section{RESEARCH METHODOLOGY}

The objective of the research is to analyse and decode how communication strategies administered in three Parkinson's disease association's Facebook pages dedicated to support Malaysian Parkinson's patients and their care givers. Malaysian Parkinson's Disease Association, Perak Parkinson's Disease Association and Penang Parkinson's Disease Association were the three fully functional Facebook pages at this time of the research. 155messages beginning August 2017 to August 2018 from all the three Facebook pages was taken for analysis. Quantitative content analysisis used to interpret the data.

Table: Face book Pages of Parkinson's Associations in Malaysia

\begin{tabular}{|c|c|c|c|c|c|}
\hline $\begin{array}{l}\text { SI. } \\
\text { No }\end{array}$ & Name & Likes & Followers & $\begin{array}{l}\text { Number of } \\
\text { Posts taken } \\
\text { for Analysis }\end{array}$ & Link \\
\hline 1. & $\begin{array}{c}\text { Malaysian Parkinson's } \\
\text { Disease Association } \\
\text { (MDPA) }\end{array}$ & 2199 & 2,232 & 121 & $\begin{array}{l}\text { https://www.facebook } \\
\text {.com/Malaysian- } \\
\text { Parkinsons-Disease- } \\
\text { Association- } \\
\text { 207738475948217/ }\end{array}$ \\
\hline 2. & $\begin{array}{c}\text { Perak Parkinson's } \\
\text { Association }\end{array}$ & 394 & 398 & 24 & $\begin{array}{l}\text { https://www.facebook } \\
\text {.com/perakparkinsons } \\
\text {.org.my/ }\end{array}$ \\
\hline 3. & $\begin{array}{l}\text { Penang Parkinson's } \\
\text { Disease Association }\end{array}$ & 344 & 356 & 10 & $\begin{array}{l}\text { https://www.facebook } \\
\text {.com/penang.parkinso } \\
\text { n/?fb_dtsg_ag=Adyxj } \\
\text { 5GmOJv_d53mlDa8i } \\
\text { hVr4AtCUI5Gtq3AG } \\
\text { 2CT9h94EQ\%3AAdz } \\
\text { FQIgB4R6V4H_rgM } \\
\text { duQIaNR5_PuLwAfc } \\
\text { pqCVZ4Ke_zqw }\end{array}$ \\
\hline & & & 2986 & 155 & \\
\hline
\end{tabular}

Based on the objectives of this research the following research questions were framed.

RQ1: What degree of observed and applied information been imparted by associations about Parkinson's disease?

RQ2: What type of health messages on Parkinson's disease are disseminated to their followers? To what extent they use pictures, videos, live videos, \#tags, and links to other web sources?

RQ3: Have associations embraced positive deviance approach to communicate information about Parkinson's disease?

Rq4: What is the level of interactivity among followers in Facebook Pages? Is there any evidence of positive behavioural change of the patients/followers in the Face book posts?

\section{RESULTS AND DISCUSSION}

155 messages posted in three Facebook pages on Parkinson's disease to support Malaysian Parkinson's patients, their families and caregivers between August 2017 and August 2018 were taken for analysis. The Facebook pages indicate a strong linkage between community workers, patients and caregivers through initiating direct participation in rehabilitation activities. 


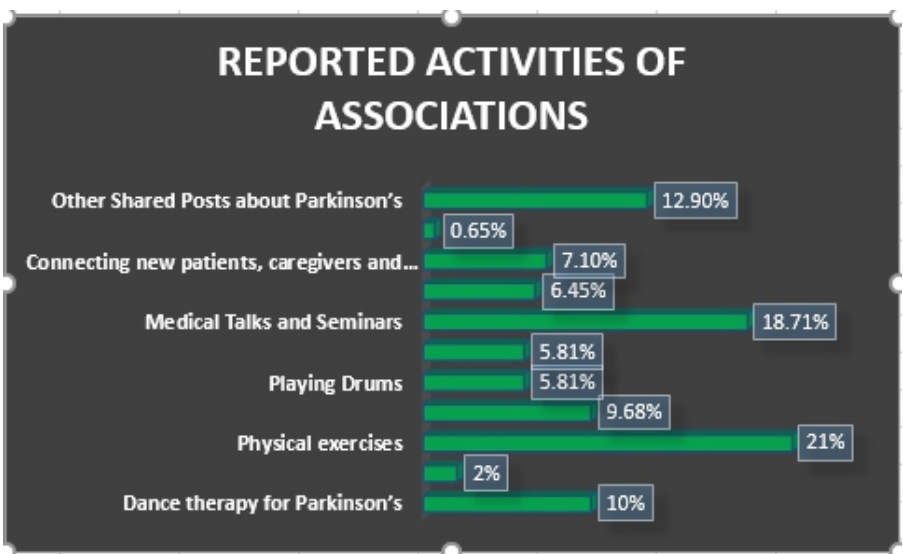

Fig 1a: Reported activities of the Parkinson's Associations

About half the posts (49\%) contained reported activities of the association mostly rendering rehabilitation for Parkinson's patients like various new forms of physical exercises, on medical talks and seminars, dancing, drumming and singing therapies, voice and speech therapy, physiotherapy, motivational sessions, and members get together (Fig.1a \& 1b). The rest of messages were invitations and reminders to participate in various activities and shared posts about Parkinson's diseases from other interest groups.



Fig 1b: Activities Reported from MDPA, Perak and Penang Parkinson's disease Association Face book Pages.

Degree of observed and applied information /know-ledge imparted through Facebook Pages

The messages were mostly applied in nature. Messages seeking to create conscious attention to Parkinson's were fewer (fig. 2a \& 2b) Direct messages on Parkinson's syndrome either motor or non-motor symptoms and their implications in patients were observed in the Facebook pages, as associations have mostly reported activities which could be used by Parkinson's patients and care takers to improve their own health behaviour. 54\% of the Facebook messages had clear pretext to explain the intention of the posts. 
The following messages indicate that content creators were not just reporting the association activates but also imparted relevant knowledge crucial for managing illness.

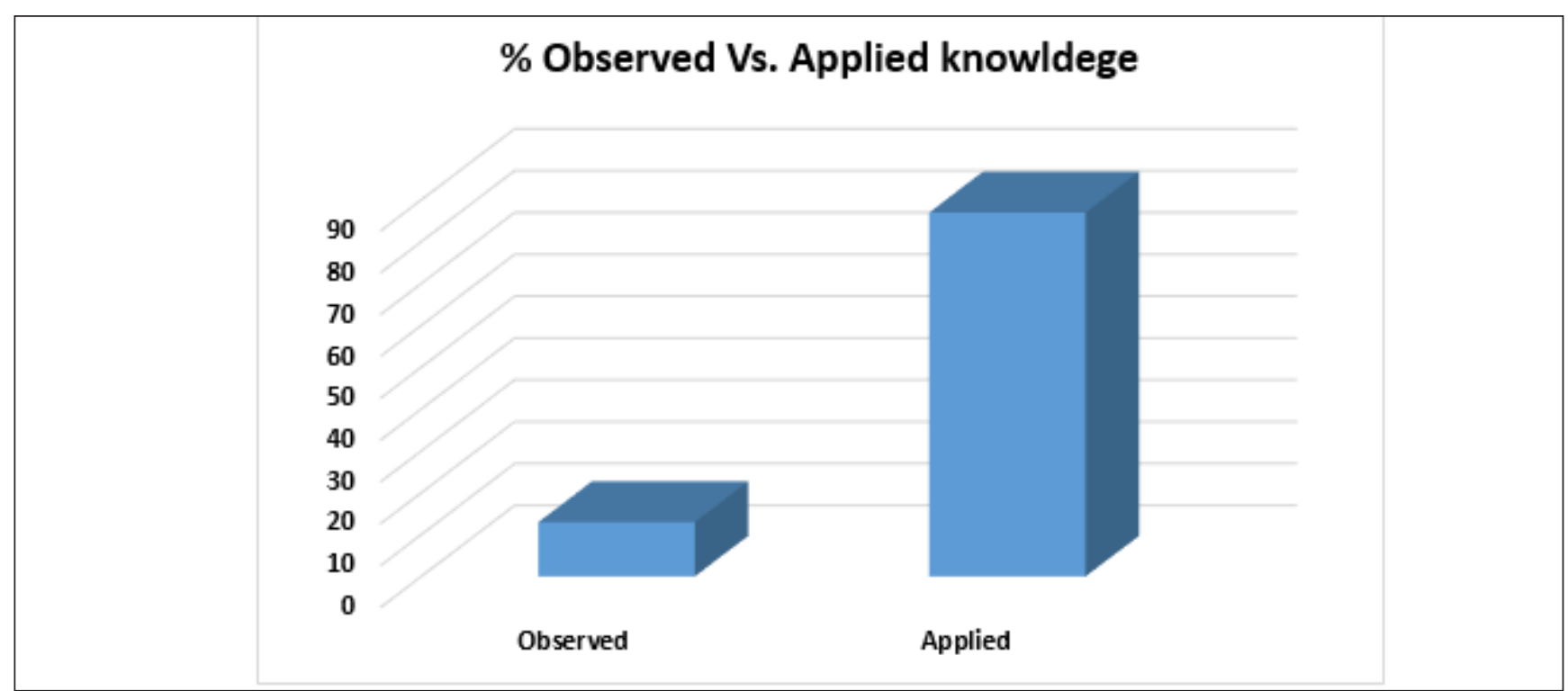

Fig2a: Degree of Observed and Applied Knowledge Imparted in Face book PagesFig2a: Degree of Observed and Applied Knowledge Imparted in Face book Pages

"Using the right mobility aid can reduce falling, reduce pain, compensate neurological impairments and improves confidence..." (MPDA, Perceived Applied Information).

"Members with Parkinson's have not yet come to terms or feel embarrassed with using a walking stick. Instead, they would rather risk falling or struggle on in pain than using it... “(MPDA, Perceived Applied Information).

"People with Parkinson's generally have a mask-like expression due to the progressive loss of motor control ability, the same way as it affects other parts of the body. It is also called hypomimia...." (MPD, Perceived Observed Information).

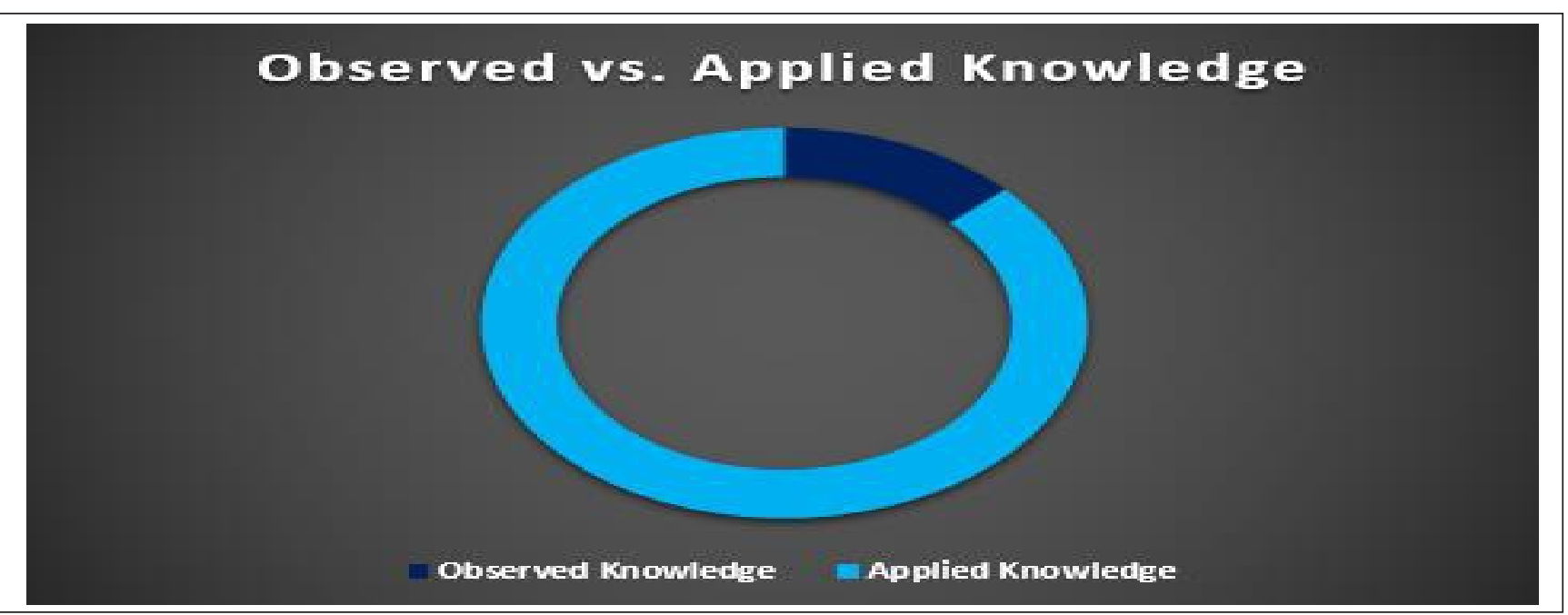

Fig. 2b: Degree of Observed and Applied Information

Applied information leads to better articulation (Fernández-Gómez and Diaz-Campo, 2017) among patients and support group comparing to any observed information. That is the very nature of social media pages with its multi-way interactivity characteristics that allows behavioural chance communication that goes beyond dissemination of factual/observed health information (Koenker et al., 2014). Further, for conditions like Parkinson's disease, until today, there is no specific medication to offer protection, or there is no 
clear causation of the disease and that makes less binding on message creators to focus on prevention information (Tan et al., 2008).

Parkinson's disease associated messages in Facebook Pages

Most of the messages were targeted to report their daily activities. Associations have been actively involved in conducting face-to-face therapeutic programmes for Parkinson's patients to improve their condition and disseminating such details through social media pages (Fig. 3a \& 3b). Few activities were organised to impart awareness, medical updates and in socializing within their associations.

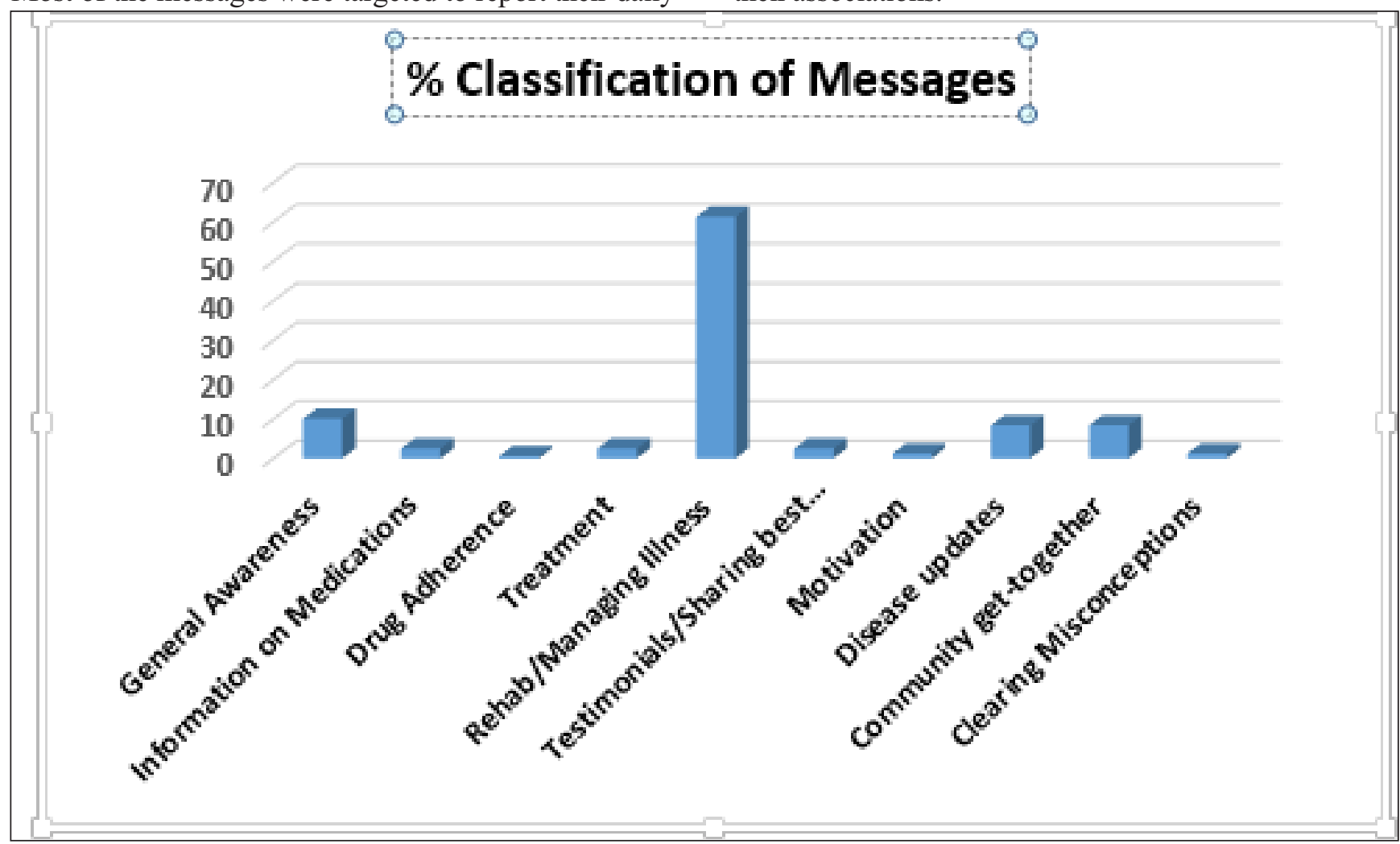

Fig 3a: Types of Health Messages of Parkinson's Disease Disseminated to Their Followers

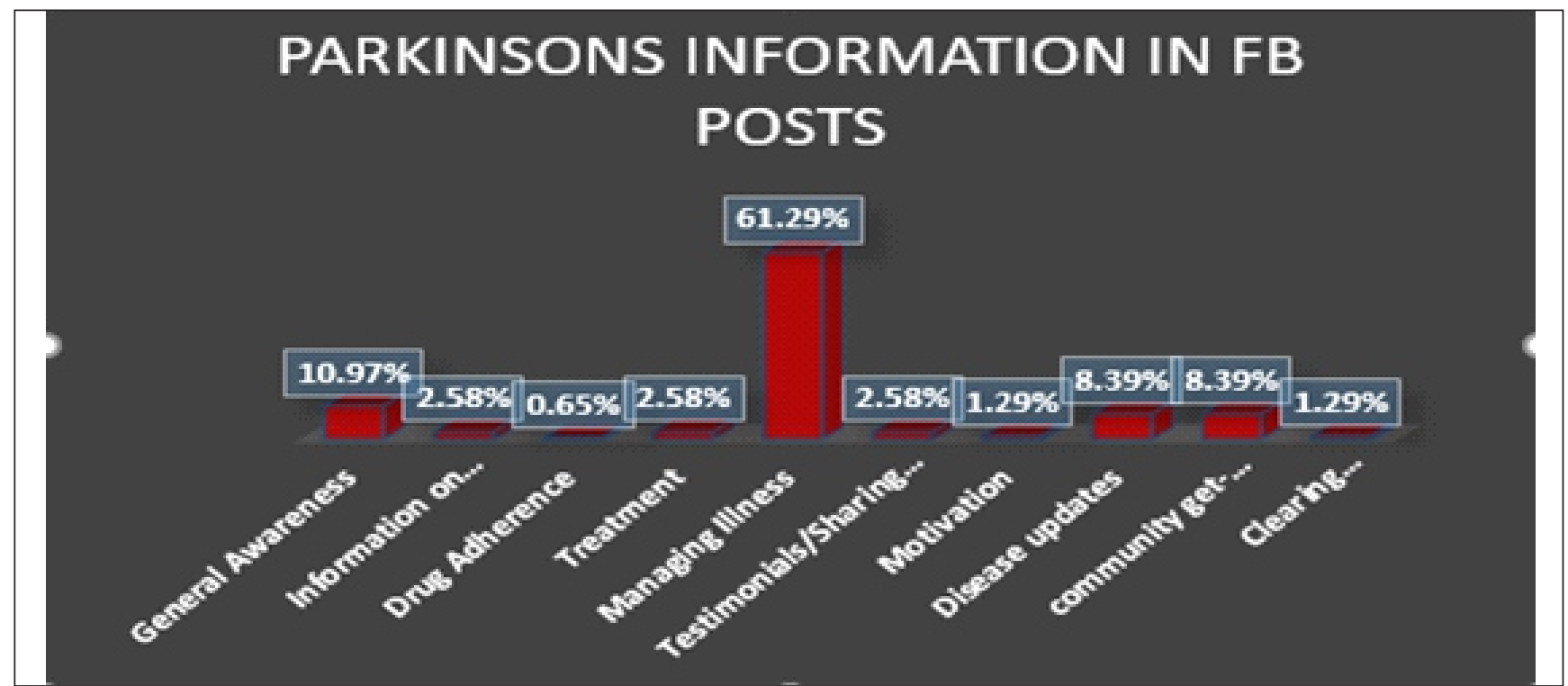

Fig. 3b: Types of Parkinson's related information posted in Face book Pages by Parkinson's associations 
There are very few messages or reported activities focusing on drug adherence and medical information, treatment options and updates, and clearing misconceptions. These messages are supported by mainly by pictures/photographs $(71 \%)$ followed by videos $(13 \%)$, links to other web sources $(8 \%)$, other YouTube links (6.5\%) and only text messages (1.5\%). No live video facility was used for covering therapeutical events. Only recorded videos of rehabilitation therapies and other activities were posted in Facebook pages. Only, Malaysian Parkinson's Disease Association did connect to other microblogging networks through tagging hashtags to broaden the understanding of Parkinson's. However, the mentioned hashtags were not frequently used. Only 10 hashtags \#musicforparkinsons, \#worldparkinsonscongress, \#danceforparkinsons, \#neveralone, \#neverGiveUp, \#danceforPD, \#Uniteforparkinsons, \#EPDA, \#Worldparkinsonsday, and \#theuncommongood were found. Regular use of hashtags could have increased Parkinson's education or on any particular topic and long-term advocacy as indicated by Guo and Saxton (2014).

\section{Enduring Positive Deviance Approach in Facebook Pages}

Evidence of $6 \%$ of messages in line with Positive Deviance Approach (PDA) is observed. Apart from sharing posts from other online sources, MPDA has reported real life patients' stories of two Malaysian residents. Joe Lacy's attentiveness to participate in marathon sessions to mitigate risk against Parkinson's complications and Leong Wai Yin's compelling practice in quilting as a therapeutic exercise that has controlled her trembling hands and improved cognitive ability. Communicating those success stories or best practices through social page attracts best attention among Parkinson's patients as they live in constant fear of becoming wheel-chair ridden has received maximum attention with 12 shares and 60 likes, the highest reach observed. In one of their association activities, a poem about Parkinson's on-off phenomena is compared to Cinderella Syndrome highlighting importance to stay active and sociable. In another post, that reads,

"There is no cure for Parkinson's, a neurological disorder and the ability to move degenerates over time but something about dancing seems to help and until now science couldn't explain why damaged signals from the brain to limbs suddenly seem to connect ...." (MDPA).This is strength-based, problem-solving Positive Deviant Approach for behavior. The approach enables the Parkinson's patients to discover existing solutions to complex problems within the community. None of the messages or activities in the social media pages has indulged in negative deviance which is a 'positive detriment' in any behavioural change communication. There were 22 highly rated positive reviews were posted by followers for MPDA appreciating their innovative ideas and practical action rendered towards Parkinson's patients. 6 positive reviews were recorded by followers for Perak Parkinson's Disease Association. So far, there is no evidence of published data on the effects of PDA reported in social media and positive behavioural chance or risk mitigation among Parkinson's disease.

\section{Level of interactivity, Social Shares and Reach}

Very poor interactivity is observed among followers in all the Facebook pages. No comments were recorded for any posts indicating no active communication between followers and association admin. It could be due to exacerbating deterioration of hands, motor disorders the very nature of the disease itself.

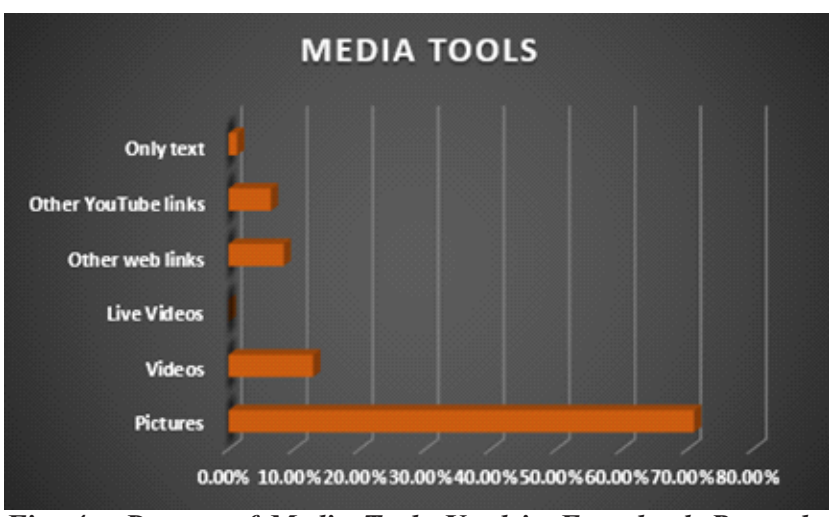

Fig. 4: Degree of Media Tools Used in Face book Pages by Parkinson's Associations

Newly added features of Facebook pages were not fully explored. For instance, live videos of events were not utilized (fig.4). No active deliberation on Parkinson's misconceptions is raised, questioned or solved. Each message posted in the Facebook pages has an average of 2 shares per posts. Responding to messages through reactions through liked and other emoticons were poor (on average 3 reactions. In terms of reach, there were 27 
videos of which 4 videos wereviewed by less than 100 followers, 5 videos viewed by less than 200 followers and 8 videos with more than 200 followers. 10 videos have no reach at all. None of the video's views ended up with active engagements among followers. This data clearly indicates that patients or followers were not actively engaging with the content contradicting many research studies stating patients and their families dealing with rare diseases are active in social media communities (Subirats et.al, 20178; Tozzi et.al, 2013).

\section{Evidence of Behavioural Changes}

In all the three Facebook pages there were meagre or no comments $(1.29 \%)$ indicating that there is no proof of behavioural changes. This falls in line with the criticism posed by Freeman et al., (2015) that social media analytics for measuring interaction or engagement like views, shares and likes may have no relationship with behavioural changes adding to the view that measuring real-life behavioural impacts in the long-term is more challenging (Taylor, 2008) cannot be wiped out. Another data which flips this belief is the face-to-face engagement in rehabilitation activities witnessed through Facebook pages indicates that direct engagement between patients and health promoters is high but the number of patients directly benefitted is yet to be ascertained. Therefore, it can be said with confidence social media pages may not be the only tool to measure behavioural changes, if any.

\section{CONCLUSION}

The relevance of popular social media site 'Facebook' in disseminating health communication for complex diseases like Parkinson's needs to be assessed at this age of evolving digital communication. This is particularly important to satisfy communication needs to newly diagnosed patients, where Parkinson's disease is hardly known. The significance of the findings establishes that social media pages do not completely engage patients in online communication for improving behavioural changes. Messages were more applied in nature, yet it cannot be said that behavioral changes were attained. Mere counts of 'likes', 'shares' and 'followers' do not indicate active use of social media pages. Nevertheless, the messages carried by these pages ignites 'mental preparedness' to cope up better with the disease.A strategized communication plan to actively use Positive Deviance Approach for better positioning of Parkinson's related health messages is crucial. Through this research, it is evident that social media pages turn out to become one of the first entry gates to look for classified communication. It acts as a gateway for newly diagnosed patients to join the community slowly shifting their communication orientation to engage in closed communication like over the top messaging applications like WhatsApp for engaging in group conversations and with more recent customised mHealth Apps. Hence, social media pages may not be a sufficient communication tool to achieve or collect evidence of behavioural changes. More research is essential to validate whether social media posts and members engagement has reduced after private mobile chat applications has entered the communication market. If arrived at such conclusions, then focusing on social media pages for achieving positive behavioural change might not be more desirable for health promoters involved in improving the lives of Parkinson's patients.

\section{ACKNOWLEDGEMENT}

We authors areimmensely grateful to Malaysian Parkinson's Disease Association, Perak Parkinson's Association, and Penang Parkinson's Disease Association all serving as a non-profit community organization for their fully functional Facebook Pages whose content served as the primary material for this research.

\section{Conflict of Interests}

The authors declare that they have no conflict of interests regarding the publication of this paper.

\section{REFERENCES}

Azmin, S., Khairul, A.A.M., Tan, H.J., Nafisah, W.Y., Raymond, A.A., Hanita, O., Shah, S.A. \& Norlinah, M.I .(2014). Nonmotor Symptoms in a Malaysian Parkinson's Disease Population. Parkinson's Disease,Pages7.

Fernández-Gómez, E. \& Díaz-Campo, J. (2017). La participación de los stakeholders de las asociaciones contra el cáncer en Facebook. Retrieved from:https://www.researchgate.net/publication/319 970916_La_participacionde_los stakeholders de las _asociaciones contra_el_cancer en_Facebook.

Freeman, B., Potente, S., Rock, V. \& McIver, J. (2015). 
Social Media Campaigns That Make a Difference: What Can Public Health Learn From The Corporate Sector and Other Social Change Marketers? Public health research \& practice, 25(2).

Guo, C. \& Saxton, G. D. (2014). Tweeting social change: How Social Media are Changing Nonprofit Advocacy. Nonprofit and VoluntarySector Quarterly, 43(1), pp.57-79.

Koenker, H., Keating, J., Alilio, M., Acosta, A., Lynch, M. \& Nafo-Traore, F. (2014). Strategic Roles for Behaviour Change Communication in a Changing Malaria Landscape. Malaria Journal, 13(1).

Kong, C. N. (2009). Parkinson's A Better Tomorrow. Negeri Sembilan Parkinson's Society. Retrieved from: http://www.nlb.gov.sg/biblio/13208330

Nkanunye, C.C. \& Obiechina, G.O. (2017). Health Communication Strategies as Gatew a y to Effective Health Promotion and Well-being. Journal of Medical Research Health Education, 1(3:13), pages 4 Effective Health Promotion and Well-being. Journal of Medical Research Health Education, 1(3:13), pages 4.

Shute, N. (2011). Web communities help patients with rare diseases. Retrieved from: http://www.npr.org/ 2011/04/04/135106113/ patients-with-rare diseases-connect-online.

Singhal, A. \& Dura, L. (2017). Positive Deviance: A Non-Normative Approach to Health and Risk Messaging. Retrieved from: http://communication. oxfordre.com/view/10.1093//acrefore/9780190228 613.001.0001/acrefore-9780190228613-e-248

Skrischer (2016). Make Your Voice Heard. A Study for all People with Parkinson's.

Statista. (2018). Number of monthly active Facebook users worldwide as of 2nd quarter 2018 (in millions). Retrieved from: https://www.statista.com /statistics/264810/number-of-monthly -active-facebook--worldwide/

Subirats, L.; Reguera, N.; Bañón, A.M.; GómezZúñiga, B.; Minguillón, J.; Armayones, M. (2018). Mining Facebook Data of People with Rare Diseases: A Content-Based and Temporal Analysis. International Journal of Environmental Resaerch and Public Health, 15(9), pages 13.

Tan, L.C., Koh, W.P., Yuan, J.M., Wang, R., Au, W.L., Tan, J.H., Tan, E.K. \& Yu, M.C. (2008). Differential Effects of Black Verus Green Tea on Risk of Parkinson's Disease in the Singaporean Chinese Health Study. American Journal of Epidemiology, 167(5), pp 553-560.

Taylor, A.H., Goodwin, V.A., Richards, S.H., Taylor, R.S. \& Campbell, J.L. (2008).The effectiveness of exercise interventions for people with Parkinson's disease: a systematic review and meta-analysis. Movement Disorders, 23(5), pp 631-640.

Tozzi, A.E., Mingarelli, R., Agricola, E., Gonfiantini, M., Pandolfi, E., Carloni, E.,Gesualdo, F, \& Dallapiccola, B. (2013). The internet user profile of Italian families of patients with rare diseases: a web survey. Orphanet Journal of Rare Diseases. 16(8), pages 9 .

Tull, K. (2017). Behaviour-change communication on health related issues (part two). Retrieved from: https:// assets.publishing.service.gov.uk/media/5bae0b024 0f0b62dd06e3246/182_BCC_on_health_related issues_PART_TWO.pdf

Twitchy Women. My Adventures with Parkinson's disease. Retrieved from: https//twitchywoman.com. /tag/positive-deviance/

Woolley, P. \& Peterson, M. (2012). Efficacy of a healthRelated Face book Social Network Site on HealthSeeking Behaviors. Social arketing Quarterly, 18(1), pp 29-39. 